\title{
UNMANNED AERIAL SYSTEMS AND SPECTROSCOPY FOR REMOTE SENSING APPLICATIONS IN ARCHAEOLOGY
}

\author{
K. Themistocleous ${ }^{a^{*}}$, A. Agapiou ${ }^{\text {a }}$, B. Cuca ${ }^{\text {a }}$, D.G. Hadjimitsis ${ }^{\mathrm{a}}$ \\ ${ }^{a}$ Cyprus University of Technology, Department of Civil Engineering and Geomatics, Remote Sensing and Geo-Environment \\ Laboratory, 2-8 Saripolou, 3036, Limassol, Cyprus- (k.themistocleous, athos.agapiou, branka.cuca, d.hadjimitsis)@cut.ac.cy
}

\author{
Commission VI, WG VI/4
}

KEY WORDS: remote sensing archaeology, UAV, ground spectroscopy, crop marks, cultural heritage

\begin{abstract}
:
Remote sensing has open up new dimensions in archaeological research. Although there has been significant progress in increasing the resolution of space/aerial sensors and image processing, the detection of the crop (and soil marks) formations, which relate to buried archaeological remains, are difficult to detect since these marks may not be visible in the images if observed over different period or at different spatial/spectral resolution. In order to support the improvement of earth observation remote sensing technologies specifically targeting archaeological research, a better understanding of the crop/soil marks formation needs to be studied in detail. In this paper the contribution of both Unmanned Aerial Systems as well ground spectroradiometers is discussed in a variety of examples applied in the eastern Mediterranean region (Cyprus and Greece) as well in Central Europe (Hungary). In- situ spectroradiometric campaigns can be applied for the removal of atmospheric impact to simultaneous satellite overpass images. In addition, as shown in this paper, the systematic collection of ground truth data prior to the satellite/aerial acquisition can be used to detect the optimum temporal and spectral resolution for the detection of stress vegetation related to buried archaeological remains. Moreover, phenological studies of the crops from the area of interest can be simulated to the potential sensors based on their Relative Response Filters and therefore prepare better the satellite-aerial campaigns. Ground data and the use of Unmanned Aerial Systems (UAS) can provide an increased insight for studying the formation of crop and soil marks. New algorithms such as vegetation indices and linear orthogonal equations for the enhancement of crop marks can be developed based on the specific spectral characteristics of the area. As well, UAS can be used for remote sensing applications in order to document, survey and model cultural heritage and archaeological sites.
\end{abstract}

\section{INTRODUCTION}

Several researchers have argue that remote sensing sensors have significant potential for archaeological investigations. Since the second half of last century, earth observation systems have been largely employed in archaeological research, thereby giving a relevant contribution in the studying of partially known sites or in the exploration of completely unknown archaeological deposits (Lasaponara and Masini, 2011; Gallo et al. 2009; Rowland and Sarris, 2007).

During the last decade, the improvement of the sensor characteristics, such as higher spatial resolution and hyperspectral data, as well the technological achievements of space technology offer new opportunities for future archaeological discoveries (Giardino, 2011).

Currently, remote sensing is being used in a variety of archaeological programs all over the world. A very promising aspect of remote sensing technology is the fact that it can be applied to identify human traces and buried archaeological remains. This task is mainly carried out using grayscale archive aerial and satellite images (Riley 1987), ground spectroradiometric hyperspectral data (Agapiou et al., 2012a; 2011a) and image interpretation of crop marks (Alexakis et al. 2011; Cavalli et al., 2007). The latest is a well-established procedure in archaeological research. Crop marks may be formed in areas where vegetation overlay near-surface archaeological remains. These features retain soil moisture with different percentage of moisture compared to the rest of the crops of an area. Depending of the type of feature, crop vigour may be enhanced or reduced by buried archaeological features.

However, the detection of such crop marks is still a difficult task since these marks may not be visible in the images if observed over different period or at different spatial/spectral resolution. Despite the technological improvements both in terms of the sensitivity of the sensors (spectral characteristics) and improvements of spatial resolution of satellite datasets, new methods are needed to improve the earth observation remote sensing technologies for supporting archaeological research.

This papers aims to present the contribution of both Unmanned Aerial Systems (UAS) as well ground spectroradiometers as discussed in a variety of examples applied in the eastern Mediterranean region (Cyprus and Greece) and in Central Europe (Hungary).

\section{GROUND SPECTRORADIOMETERS AND ARCHAEOLOGICAL RESEARCH}

\subsection{Atmospheric correction of archive satellite data}

Although satellite imagery and vegetation indices (e.g., NDVI) are systematically used for the detection of crop marks, atmospheric corrections are often not applied in such studies. However, satellite images need to be radiometric corrected before being subjected to any post-processing techniques. Radiometric corrections are distinguished between calibrations, de-striping approaches, atmospheric corrections and removal of 
data errors or flaws. Radiometric correction is considered to be a more difficult technique than geometric correction since the distributions and intensities of these effects are often inadequately known. Despite the variety of techniques used to estimate the atmospheric effect, the atmospheric correction remains a difficult task in the pre-processing of image data. Furthermore, based on the target under investigation, its impact is an important issue in the retrieval of true and correct outcomes. The effects of the atmosphere on spectral signatures and vegetation indices have become an important issue in relevant scientific literature since the 1980s (e.g. Duggin and Piwinski, 1984). Atmosphere is a primary source of noise for accurate measurement of surface reflectance with optical remote sensing. In many archaeological applications, there is a need to use up-to date satellite imagery as well as archived multi-temporal data. Therefore, the use of physical-based atmospheric correction can be very difficult to apply, since auxiliary data may not exist for the case study. Moreover, image-based algorithms can be performed easier, even to archive data, regardless of satellite sensor and satellite characteristics. One of the simplest, fully-imaged based, is the Darkest Pixel (DP) algorithm.

In this example (see Agapiou et al. 2011b) an archive series of Landsat dataset is being used over the archaeological sites of "Nea Paphos" and "Palaepaphos" in Cyprus (Figure 1). The results have shown that the general trend of the NDVI from the phenological cycle of the crops remains the same without any atmospheric corrections (Figure 2). However, if absolute values are needed for comparison between two different dates, then atmospheric correction procedures should be applied first. The results have been confirmed with ground spectroradiometers.
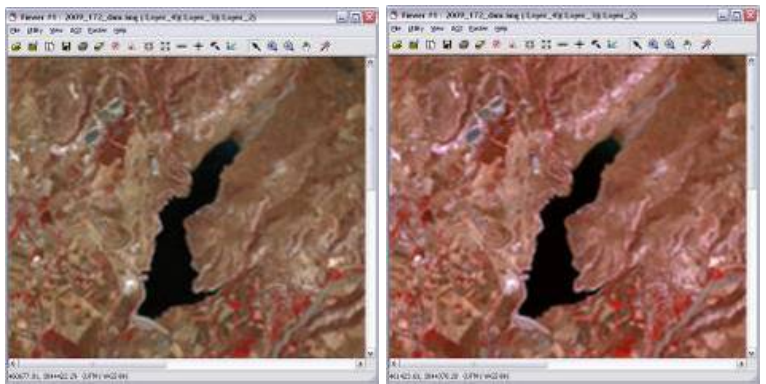

Figure 1. Landsat image before (left) and after (right) the atmospheric correction (from Agapiou et al. 2011b)

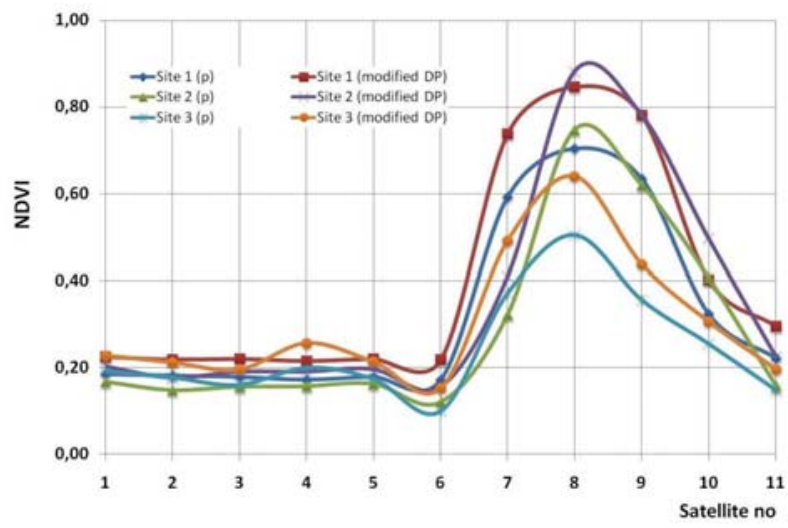

Figure 2. Phenological observations of crops using NDVI before and after the application of the atmospheric correction (from Agapiou et al. 2011b)

\subsection{Detection of the optimum period and spectral characteristics for monitoring crop marks}

The formation of crop marks is very close related with the environmental and meteorological conditions of the area. In order to identify the optimum period for monitoring as well the detection of crop marks phenological observations were carried out using ground spectroradiometers. Experiments were carried out in controlled environment as shown in Figure 3 (Agapiou et al. 2013a).
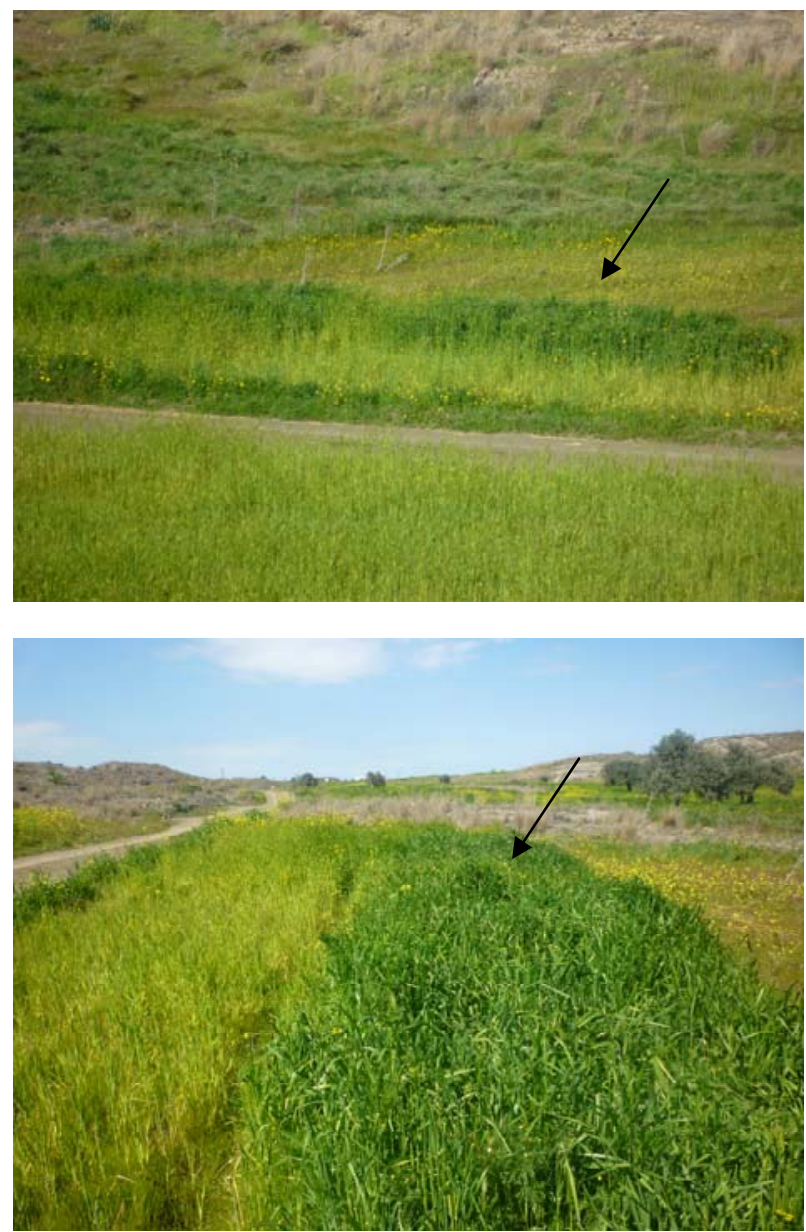

Figure 3. Formation of crop marks in controlled environment.

The whole dataset from two study areas cultivated with barley and wheat crops was analysed separately and the final outcomes came to similar conclusions regarding the spectral regions where spectral enhancement is maximized. It was found that multispectral sensors, which are sensitive to near infrared wavelengths, provide evidence of crop reflectance variations due to buried archaeological remains. In hyperspectral sensors, these spectral regions were found around $700 \mathrm{~nm}$ to $800 \mathrm{~nm}$ (near infrared and red edge).

In addition the results indicate that the best period for monitoring crop marks using remote sensing data is during the full emergence stage of the crops and boot stage of the plants. This study found that the best phenophase is around the beginning of the boot stage. This conclusion was compatible for both case studies areas, even though many differences are recorded from these sites, including differences in types of crops, soil characteristics, cultivations techniques and climate 
conditions. Based from this analysis the best phenophase for monitoring crop marks is limited to approximately 15 days.

A hyperspectral archaeological index was proposed to enhance the detection of crop marks (Agapiou et al. 2013a). The index was successfully applied in a variety of sites indicating enhanced performance compared to other known established algorithms (Figure 4)

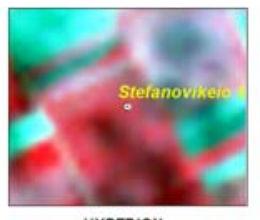

HYPERION
$($ NIR-R.G, B45-B35-B25)

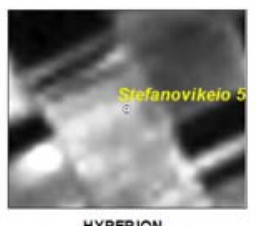

HYPERION Ratio (R75)
(B40/B35)

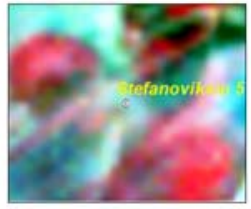

Landsat TM (NIR-G-B)

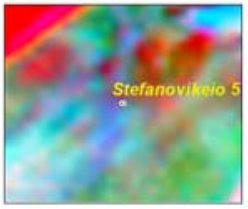

Landsat TM (PCA)
$2007-07.26$

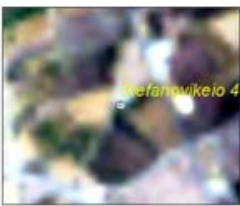

HYPERION
(R-G.B, B30-B22-B15)

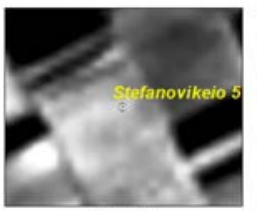

HYPERION
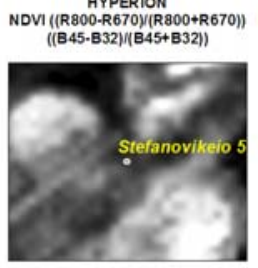

Landsat TM (NDVI)

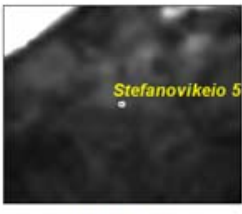

$\underset{2007-07-10}{\operatorname{Landsat} T M(S R)}$

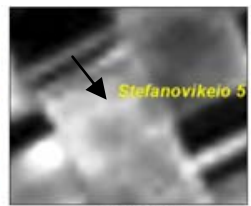

HYPERION
(A.1., R800-R700, B45-B35)

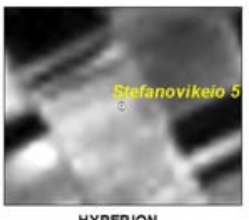

HYPERION
H.ON ((B 4 40-B35)/(B40+B35))

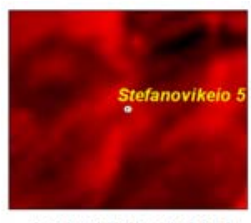

Landsat TM (Tasseled Cap)

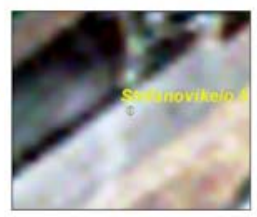

Landsat TM (RGB)

Figure 4. Application of different algorithms for the detection of crop marks in EO- Hyperion and Landsat data over the archaeological site of Stefanovikeio in Thessaly (Greece). The proposed archaeological index ( $1^{\text {st }}$ row, $3^{\text {rd }}$ column) was able to detect the crop mark.

\subsection{New orthogonal equations for detection of crop marks}

New linear orthogonal equations for the enhancement of crop marks, for several existing medium and high resolution satellite sensors have been recently proposed by the authors (Agapiou et al. 2013b). These linear transformations are based on the physical characteristics of crop marks, vegetation and soil. The algorithms are based on the work of Kauth-Thomas also known as Tasseled Cap transformation (K-T algorithm), in order to detect vegetation in satellite data. To develop specific linear transformations for the enhancement of crop marks using satellite images, the authors have followed an alternative methodology based on simulated data taken from ground spectroradiometer. Systematic spectroradiometric campaigns were organized into a test field to record ground data during the whole phenological cycle of the crops. In this way, the dynamic nature of formation of crop marks was also observed, and pure reflectance values from crop marks, vegetation and bare soil were acquired.
Several existing high and medium resolution satellite data have been evaluated for the purpose of this study. Specifically, the GeoEye-1; ASTER; IKONOS; Landsat 7 ETM+; Landsat 4 TM; QuickBird as well as WorldView-2 imagery were assessed for their capabilities to detect crops marks. The linear coefficients (Figure 5) for each dataset were calculated separately since each sensor has a different RSR filter and different spectral range of each particular bandwidth (from visible to the NIR part of the spectrum).

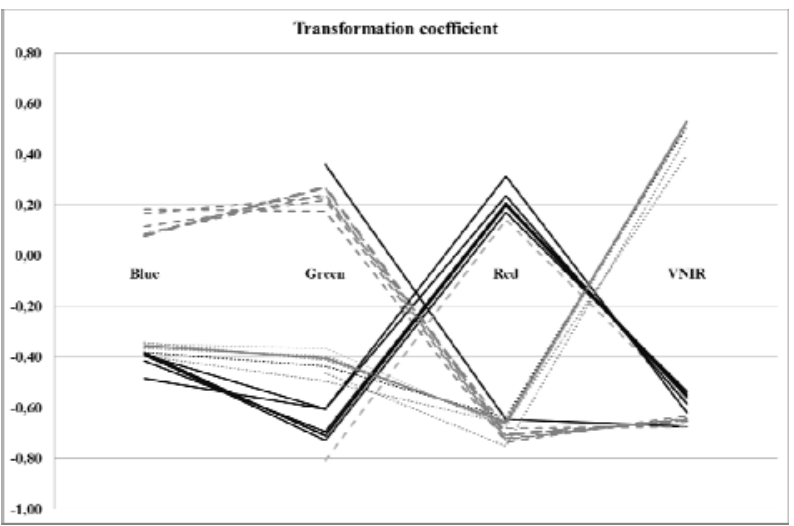

Figure 5. Distribution of the linear coefficient for each spectral bandwidth. Solid line shows the coefficients for the crop mark component, dashed line the coefficients for the soil component and dot line the coefficients for the vegetation component.

In order to evaluate the proposed transformations for each sensor, different archaeological sites were evaluated. In Figures 6 and 7, the examples of GeoEye and QuickBird images from the western part of Elis archaeological site is demonstrated. As shown in Figure 6e and $7 \mathrm{fthe}$ proposed equations were able to enhance better the still un-excavated archaeological site.

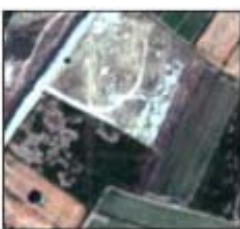

(a)

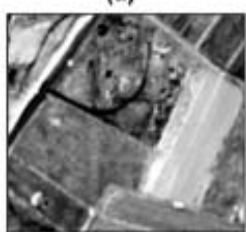

(d)

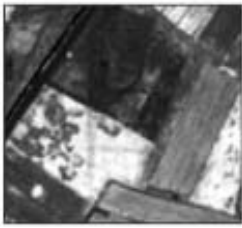

(g)

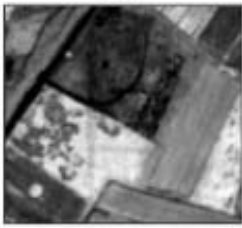

(j)

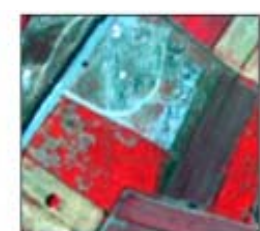

(b)

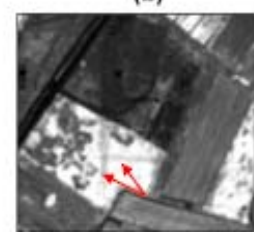

(e)

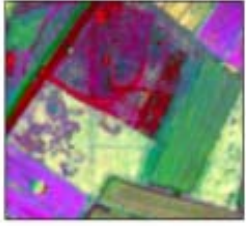

(h)

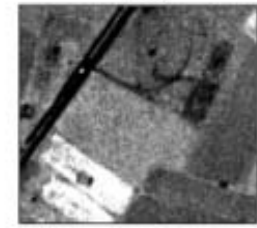

(k)

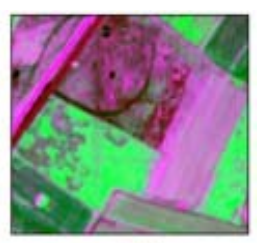

(c)

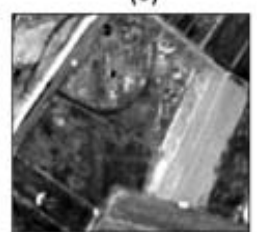

(f)

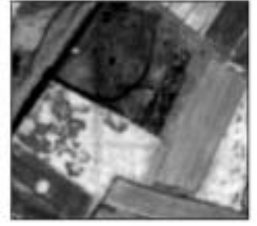

(i)

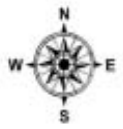

$02550 \quad 100$ Meters

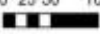


Figure 6. Results from GeoEye-1 dataset from the western part

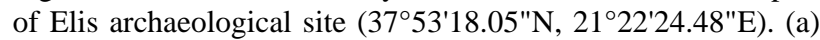
RGB composite; (b) NIR-R-G composite; (c) Proposed linear transformation RGB pseudo colour; (d) first component; (e) second component; (f) third component; (g) NDVI; (h) PCA composite; (i) first PCA component; (j) second PCA component and $(\mathrm{k})$ third PCA component (from Agapiou et al 2013b)

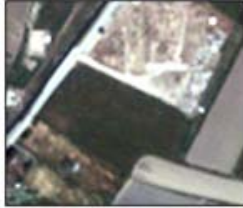

(a)

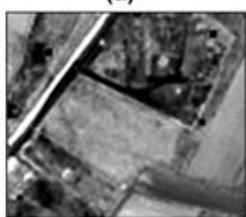

(d)

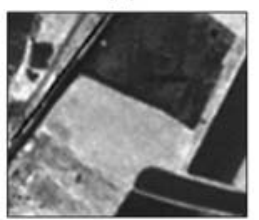

(g)

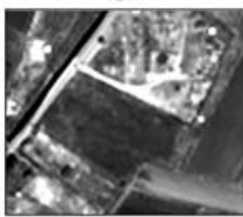

(j)

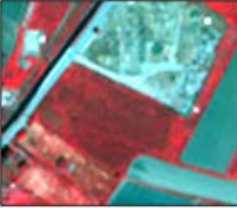

(b)

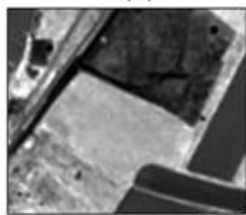

(e)

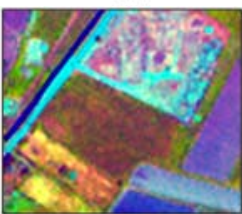

(h)

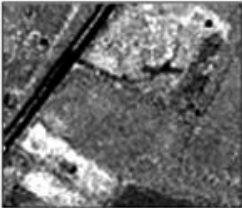

(k)

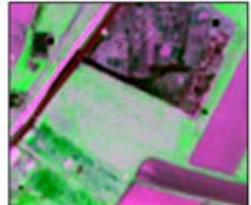

(c)

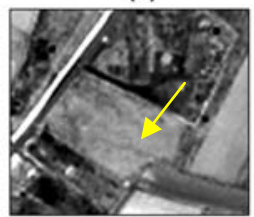

(f)

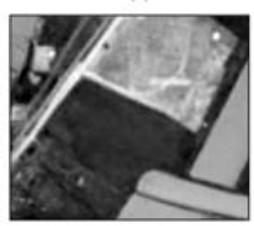

(i)

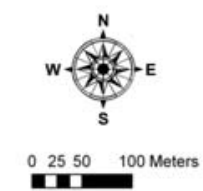

$02550 \quad 100$ Meters printed with high resolution using a 3D printer (Themistocleous et al, 2015).

In this paper, aerial images generated from an UAV survey of a portion of the archaeological site of Curium in the south-west of Cyprus were used to illustrate methods of site documentation and archaeological survey to identify buried remains. NDVI technques using the combination of visible and near infrared cameras were used to identify vegetation stress and crop marks.

The RGB ortho-mosaic of the archaeological site can be used for the detection of buried archaeological features (Figure 8). Such features can be detected mainly from linear crop marks (Agapiou et al, 2013a; Agapiou and Hadjimitsis 2011a). In the specific flight, the possibility of identifying crop marks from a limited spectral range (visible bands) were also examined. Using this method, crop marks were detected in the western part of the survey area close to the coastline. Although the result are preliminary, since no other remote sensing technique (e.g. geophysics) has been employed to this area, the linear features as seen from the ortho-mosaic, as well their orientation (similar to excavated areas) indicate that archaeological remains are present in the area. The area may be the location of a Roman period port according to Leonard (1995).
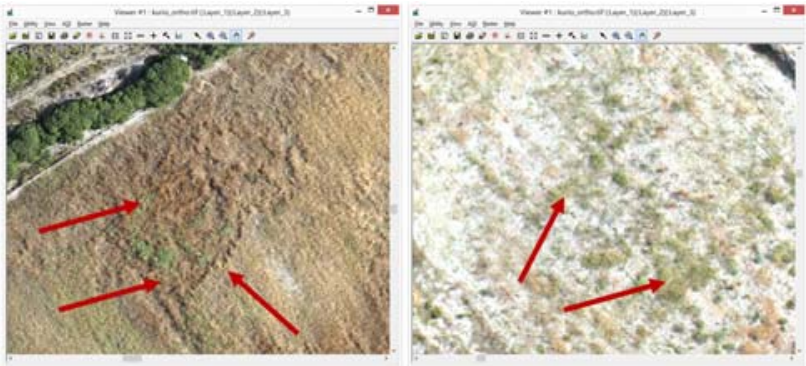

Figure 8. Detection of crop marks close to the sea as seen from the RGB ortho-mosaic

Further analysis using spatial filters has been applied to the RGB ortho-mosaic in order to improve the photointerpretation of the images. Such simple image enhancements techniques applied to vegetation indices (e.g. IRG using both red and green band) can be fully exploited to detect un-excavated sites (Figure 9).

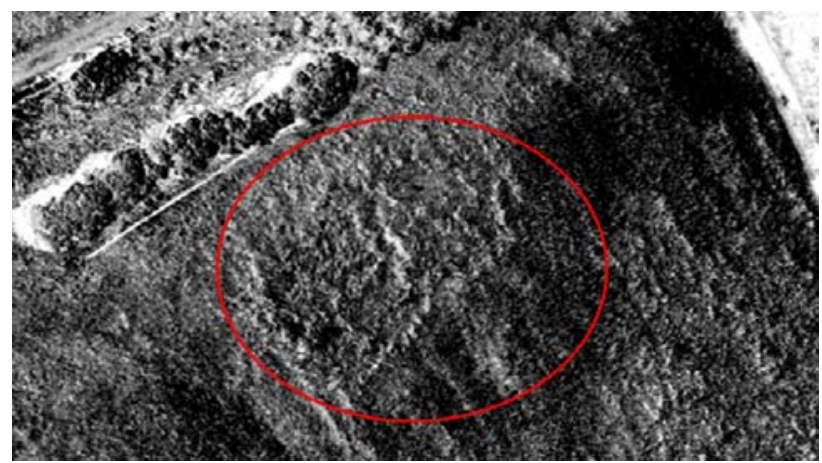

Figure 9. Image enhancement of the image applied to the IRG vegetation index

It should be noted that using UAV flights during different periods of the season can improve further the archaeological research, minimizing any false-true result from single campaigns. 


\section{CONCLUSIONS}

The study indicated that ground data and the use of UAVs can provide an increased insight for studying the formation of crop and soil marks. UAVs are an extremely important tool for archaeologists as they provide a cost-effective and efficient manner to acquire high spatial resolution data with high temporal frequencies over a large area. New algorithms such as vegetation indices, linear orthogonal equations for the enhancement of crop marks can be developed based on the specific spectral characteristics of the area. Aerial imagery from UAVs can also allow the rapid generation of 3D digital surface models for documentation and model reconstruction. Future research in this area can include the use of algorithms using the thermal and multispectral sensors on the UAV in order to attain greater information from the area of interest to provide a more precise location of the archaeological remains in the area. In this way, the UAVs can be combined with field surveys such as the use of ground penetrating radars to identify the geometry and location of the remains, thereby minimizing the amount of fieldwork required at an archaeological site. Additional research will also examine spectral signatures acquired from UAVs fitted with spectroradiometers (Themistocleous, 2014) to identify crop marks in larger areas.

\section{ACKNOWLEDGEMENTS}

We wish to thank the Remote Sensing Laboratory of the Cyprus University of Technology and the Cyprus Remote Sensing Society for the use of their equipment.

\section{REFERENCES}

Agapiou A., Hadjimitsis G. D., 2011a. Vegetation indices and field spectroradiometric measurements for validation of buried architectural remains: verification under area surveyed with geophysical campaigns. Journal of Applied Remote Sensing 5, 053554, http://dx.doi.org/10.1117/1.3645590

Agapiou A, Hadjimitsis DG, Papoutsa C, Alexakis DD, Papadavid G. 2011b. The Importance of Accounting for Atmospheric Effects in the Application of NDVI and Interpretation of Satellite Imagery Supporting Archaeological Research: The Case Studies of Palaepaphos and Nea Paphos Sites in Cyprus. Remote Sensing.3(12), pp. 2605-2629.

Agapiou A., Hadjimitsis G. D., Alexakis D. Sarris A., 2012a. Observatory validation of Neolithic tells ("Magoules") in the Thessalian plain, central Greece, using hyperspectral spectroradiometric data. Journal of Archaeological Science, 39 (5), pp. 1499-1512, ISSN 0305-4403, 10.1016/j.jas.2012.01.001.

Agapiou A., Hadjimitsis D. G., Sarris A., Georgopoulos A.and Alexakis D. D., 2013a. Optimum Temporal and Spectral Window for Monitoring Crop Marks over Archaeological Remains in the Mediterranean region, Journal of Archaeological Science, 40 (3), pp. 1479-1492.

Agapiou A., Alexakis, D.D., Sarris, A., Hadjimitsis, D.G., 2013b. Orthogonal Equations of Multi-Spectral Satellite Imagery for the Identification of Un-Excavated Archaeological Sites. Remote Sensing, 5, pp. 6560-6586.

Alexakis D.., Sarris A., Astaras T., Albanakis K. 2011. Integrated GIS, remote sensing and geomorphologic approaches for the reconstruction of the landscape habitation of Thessaly during the Neolithic period. Journal of Archaeological Science 38, pp. 89-100.

Cavalli R.S., Colosi F., Palombo A., Pignatti S., Poscolieri M., 2007. Remote Hyperspectral Imagery as a Support to Archaeological Prospection. Journal of Cultural Heritage 8, pp. 272-283.

Duggin, M.J., Piwinski, D. 1984. Recorded radiance indices for vegetation monitoring using NOAA AVHRR data; atmospheric and other effects in multitemporal data sets. Applied Optics, 23, pp. 2620-2623.

Gallo D., Ciminale M., Becker H., Masini, N., 2009. Remote sensing techniques for reconstructing a vast Neolithic settlement in Southern Italy. Journal of Archaeological Science 36(1), pp. 43-50, ISSN 0305-4403, 10.1016/j.jas.2008.07.002.

Giardino J. M., 2011. A history of NASA remote sensing contributions to archaeology. Journal of Archaeological Science 38(9), pp. 2003-2009.

Lasaponara R., Masini N., 2011. Satellite remote sensing in archaeology: past, present and future perspectives, Journal of Archaeological Science 38 (9), pp. 1995-2002.

Leonard J. R. Evidence for Roman Ports, Harbours and Anchorages in Cyprus, in V. Karageorghis \& D. Michaelides, Proceedings of the Symposium Cyprus and the Sea, Nicosia: University of Cyprus (1995).

Riley, D. N. 1987. Air photography and archaeology. Duckworth, London.

Rowlands A., Sarris A., 2007. Detection of exposed and subsurface archaeological . using multi-sensor remote sensing. Journal of Archaeological Science 34 (5), 795-803.

Themistocleous K., 2014. The use of UAV Platforms for Remote Sensing Applications: Case Studies In Cyprus. Proceedings of the Second International Conference on Remote Sensing and Geoinformation of Environment, 7-10 April, 2014.

Themistocleous, K., Agapiou, A., King, H.M., King, N., Hadjimitsis, D.G. 2014a. More Than a Flight: The Extensive Contributions of UAV Flights to Archaeological Research - The Case Study of Curium Site in Cyprus. Proceedings of the EuroMed 2014 Conference, 3-8 November, 2014.

Themistocleous, K., Agapiou, A., Cuca, B., Hadjimitsis, D.G., 2014b. 3D Documentation Of Cultural Heritage Sites, Proceedings of the EuroMed 2014 Conference, 3-8 November, 2014.

Themistocleous, K., Ioannides, M., Agapiou, A., Hadjimitsis, D.G., 2015. The Methodology Of Documenting Cultural Heritage Sites Using Photogrammetry, UAV And 3D Printing Techniques: The Case Study Of Asinou Church In Cyprus. Proceedings of the Third International Conference on Remote Sensing and Geoinformation of Environment, 16-19 March, 2015. 